\title{
СФЕРА КУЛЬТУРЫ И ДОСУГА КАК ОСНОВНАЯ СОСТАВЛЯЮЩАЯ ЭКОНОМИКИ ВПЕЧАТЛЕНИЙ
}

\author{
Н. И. Лыгина
}

Орловский государственный университет экономики и торговли

Н. А. Паршиков

Орловский государственный институт культуры

\author{
О. В. Рудакова
}

Российская академия народного хозяйства и государственной службы при Президенте Российской Федерации (Среднерусский институт управления) Орловский государственный институт культуры

Поступила в редакцию 1 декабря 2019 г.

\begin{abstract}
Аннотация: анализ тенденций социально-экономического развития в начале XXI в. позволяет утверждать, что идет процесс формирования экономики нового типа, а именно экономики впечатлений. Современный потребитель, принимая решение о покупке товара или услуги, все чаше руководствуется тем, какими эмоциями и впечатлениями будет сопровождаться эта покупка. Экономика впечатлений является современным продуктом развития сферы культуры, поскольку именно впечатления чаще всего выступают основой культурной индустрии и сферы развлечений.
\end{abstract}

Ключевые слова: сфера услуг, сервисная револючия, впечатления, экономика впечатлений, добавленная стоимость, сочиально-культурная сфера, финансирование культурыл.

\begin{abstract}
XXIth century makes it possible to state that a new type of economy - the economy of impressions - is being formed now. Making a decision to buy a product or service modern consumer is more often guided by the emotions and impressions he has making this purchase. The impressions economy is a modern product of the culture development. They are impressions that are often the basis of culture industry and entertainment.
\end{abstract}

Key words: service sector, service revolution, impressions, impression economy, value added, social and cultural sphere, culture financing.

В настоящее время человечество переживает очередную революцию в системе производства. В доиндустриальном обществе источником добавленной стоимости выступала сырьевая экономика, в индустриальном - товарная экономика, в постиндустриальном - сфера услуг. Сегодня идет очередной процесс миграции стоимости, она мигрирует в экономику впечатлений. Следует согласиться с утверждением, что в цепочке «сырье - товар - услуга - впечатление» доля добавленной стоимости шаг за шагом растет и основной ее удельный вес приходится именно на впечатление [1]. Добавленная стоимость, создаваемая в сырьевой экономике, в представленной выше цепочке оказывается наименьшей.

В странах с высоким уровнем социально-экономического развития в последние десятилетия

(С) Лыгина Н. И., Паршиков Н. А., Рудакова О. В., 2020 отчетливо прослеживается тенденция снижения материальной составляющей в стоимости товаров и услуг (около 10-15 \%) при увеличении доли затрат на приобретение знаний и информации [2]. По этой причине мировые сырьевые рынки постепенно исчезают в результате слияний и поглощений, для них характерна высокая степень монополизации. В сравнении с сырьевой экономикой значительно большая добавленная стоимости формируется в товарной экономике. Однако товарные рынки сигнализируют сегодня о неблагоприятных тенденциях. Коммодитизация, представляющая собой процесс перехода продукта из марочной категории в категорию рядовых продуктов и обусловленная постоянным совершенствованием производственных технологий, уже превратилась в серьезную проблему этих рынков [3]. В экономике услуг только начинают возникать похожие трудности. 
Сегодня впечатления становятся самостоятельным и дорогостоящим продуктом и объектом купли-продажи. За впечатление потребитель готов платить максимальное количество денег [4]. Современный потребитель, принимая решение о покупке товара или услуги, все чаще руководствуется тем, какими эмоциями и впечатлениями будет сопровождаться эта покупка. Впечатление представляет собой, по сути, четвертую экономическую категорию, принципиально отличающуюся от сырья, товаров и услуг. В большинстве случаев товар представляет собой материальное, стандартизированное благо, которое передается потребителю по описи. Услуга выступает как нематериальное, персонализированное благо, получаемое по требованию отдельного субъекта. Впечатление является запоминающимся личным ощущением (переживанием), сохраняемым в памяти субъекта [5-6]. Без впечатлений не могут существовать ни товар, ни услуга. Каждый товар производит положительное или отрицательное впечатление на потребителя. При использовании какой-либо услуги потребитель испытывает определенные эмоции.

Анализ тенденций социально-экономического развития в начале XXI в. позволяет утверждать, что идет процесс формирования экономики нового типа, а именно экономики впечатлений. Данный термин впервые употребили в 1999 г. американские маркетологи Д. Пайн и Д. Гилмор, рассмотревшие новую экономику как новый подход к производству и продвижению товара или услуги, основанный на создании положительного впечатления как от производства и продвижения, так и от получения товара или услуги, а также от последующих за этим ощущений [5-6]. Согласно пирамиде потребностей Маслоу становление экономики впечатлений является вполне естественной ступенью развития. Поскольку после удовлетворения базовых физиологических потребностей, потребностей в безопасности, в принадлежности, потребности в уважении возникают познавательные, эстетические потребности, потребности в самореализации. Мир вступил в эпоху впечатлений, где ведущие компании предлагают не товар или услугу, а стиль жизни. Современная экономика впечатлений строится на аспекте получения положительных эмоций. Выделяют следующие тенденции, свидетельствующие о зарождении экономики впечатлений:

- большая доля услуг в ВВП;

- рост отраслей экономики и рынков, напрямую связанных с созданием впечатлений: индустрия развлечений, киноиндустрия, рынок гостиничных и ресторанных услуг, туризм;

- рост услуг как дифференциаторов товарного предложения компании;

- рост эмоциональных факторов и факторов, связанных с созданием впечатлений, в коммуникационных кампаниях по продвижению товаров и услуг [7].

Превращение сферы услуг в доминирующий сектор народного хозяйства стало закономерностью развития современной цивилизации и предвестником становления экономики впечатлений. Ускоренный рост сферы услуг получил название «сервисной революции». Отличительной чертой сферы услуг является создание невещных благ. Результаты труда в отраслях этой сферы не принимают предметной формы, а выступают в виде полезного эффекта, неотделимого от самой деятельности.

Как следует из данных, представленных в табл. 1, в 2017 г. на сельское хозяйство пришлось $6,4 \%$ общего объема мирового производства, а вклад промышленного производства $-30 \%$. На сегодняшний день сфера услуг представляет собой крупнейший сектор мировой экономики, так как на нее приходится $63 \%$ планетарного продукта. Крупнейшим производителем услуг являются США, где на долю рассматриваемого сектора приходится 80,2 \% ВВП. В сфере услуг Китая создается 52,2 \% ВВП, и по объему производства этого сектора страна занимает второе место в мире. На третьем месте в рейтинге расположилась Япония. Следует отметить, что Чад имеет самую низкую долю сферы услуг в ВВП - 27 \%. В начале XXI в. в 201 стране сфера услуг стала ведущим сектором экономики. Третичный сектор обеспечивает более 80 \% своего ВВП в экономике 30 государств [8]. В России третичный сектор обеспечивает 915,2 млрд долл. (13-е место), его вклад в ВВП страны составляет $62,3 \%$.

Как уже отмечалось, для экономики впечатлений характерен рост отраслей экономики и рынков, напрямую связанных с созданием впечатлений. Можно утверждать, что сфера культуры и досуга представляет собой одну из главных составляющих экономики впечатлений. Экономика впечатлений является современным продуктом развития сферы культуры, поскольку именно впечатления чаще всего выступают основой культурной индустрии и сферы развлечений [10]. Развлечения выступают как старейший и самый известный вид впечатлений, производство которых 
Структура ВВП некоторых стран мира в 2017 г. [9]

\begin{tabular}{|c|c|c|c|c|c|c|c|c|c|c|c|}
\hline \multirow[b]{2}{*}{ Место } & \multirow[b]{2}{*}{ Страна } & \multirow[b]{2}{*}{$\begin{array}{l}\text { ВВП, млрд } \\
\text { долл. США }\end{array}$} & \multicolumn{3}{|c|}{ Сельское хозяйство } & \multicolumn{3}{|c|}{ Промышленность } & \multicolumn{3}{|c|}{ Сфера услуг } \\
\hline & & & ВВП & место & $\begin{array}{l}\% \text { от } \\
\text { ВВП }\end{array}$ & ВВП & место & $\begin{array}{l}\text { \% от } \\
\text { ВВП }\end{array}$ & ВВП & место & $\begin{array}{l}\text { \% от } \\
\text { ВВП }\end{array}$ \\
\hline 1 & США & 19360 & 174,2 & 3 & 0,9 & 3659 & 2 & 18,9 & 15526,7 & 1 & 80,2 \\
\hline 2 & Китай & 11940 & 991,0 & 1 & 8,3 & 4716,3 & 1 & 39,5 & 6232,7 & 2 & 52,2 \\
\hline 3 & Япония & 4884 & 48,8 & 13 & 1 & 1450,5 & 3 & 29,7 & 3384,6 & 3 & 69,3 \\
\hline 4 & Германия & 3652 & 21,9 & 31 & 0,6 & 1099,2 & 4 & 30,1 & 2530,8 & 4 & 69,3 \\
\hline 5 & Франция & 2575 & 51,5 & 11 & 2 & 517,6 & 7 & 20,1 & 2005,9 & 6 & 77,9 \\
\hline 6 & $\begin{array}{l}\text { Объединенное } \\
\text { Королевство } \\
\end{array}$ & 2565 & 15,4 & 36 & 0,6 & 487,4 & 8 & 19 & 2062,3 & 5 & 80,4 \\
\hline 7 & Индия & 2439 & 375,6 & 2 & 15,4 & 560,9 & 6 & 23 & 1499,9 & 8 & 61,5 \\
\hline 8 & Бразилия & 2081 & 129,0 & 4 & 6,2 & 437,0 & 12 & 21 & 1514,9 & 7 & 72,8 \\
\hline 9 & Италия & 1921 & 40,3 & 17 & 2,1 & 461 & 10 & 24 & 1419,6 & 9 & 73,9 \\
\hline 10 & Канада & 1640 & 27,9 & 25 & 1,7 & 460,8 & 11 & 28,1 & 1151,3 & 10 & 70,2 \\
\hline 11 & Южная Корея & 1530 & 33,7 & 22 & 2,2 & 601,3 & 5 & 39,3 & 891,9 & 14 & 58,3 \\
\hline 12 & Россия & 1469 & 69 & 7 & 4,7 & 475,9 & 9 & 32,4 & 915,2 & 13 & 62,3 \\
\hline 13 & Австралия & 1390 & 50 & 12 & 3,6 & 362,8 & 14 & 26,1 & 977,2 & 11 & 70,3 \\
\hline 14 & Испания & 1307 & 33,9 & 21 & 2,6 & 303,2 & 16 & 23,2 & 969,8 & 12 & 74,2 \\
\hline 15 & Мексика & 1142 & 44,5 & 15 & 3,9 & 360,8 & 15 & 31,6 & 730,9 & 15 & 64 \\
\hline 29 & Нигерия & 394,8 & 85,3 & 6 & 21,6 & 72,2 & 47 & 18,3 & 237,3 & 32 & 60,1 \\
\hline 30 & Норвегия & 392,1 & 9,4 & 47 & 2,4 & 121,9 & 29 & 31,1 & 260,7 & 28 & 66,5 \\
\hline 45 & Вьетнам & 223,3 & 34,2 & 20 & 15,3 & 74,6 & 46 & 33,3 & 92,2 & 55 & 41,3 \\
\hline 61 & Кувейт & 118,3 & 0,4 & 150 & 0,4 & 69,4 & 50 & 58,7 & 48,4 & 69 & 40,9 \\
\hline 63 & Украина & 104,1 & 14,6 & 37 & 14 & 28,9 & 65 & 27,8 & 60,6 & 62 & 58,2 \\
\hline 104 & Уганда & 26,4 & 6,8 & 63 & 25,8 & 6,1 & 110 & 23,2 & 13,5 & 108 & 51 \\
\hline 149 & Нигер & 7,3 & 3 & 97 & 41,5 & 1,3 & 154 & 18,1 & 2,9 & 165 & 40,4 \\
\hline 155 & Сомали & 6,5 & 3,9 & 84 & 60,2 & 0,5 & 179 & 7,4 & 2,1 & 170 & 32,5 \\
\hline 197 & Гвинея-Бисау & 1,3 & 0,6 & 145 & 44,1 & 0,1 & 196 & 12,9 & 0,6 & 201 & 43 \\
\hline
\end{tabular}

связано с индустрией развлечений и досуга. Развлекательный элемент в настоящее время проникает практически в каждый сегмент жизни общества. Существует мнение о формировании целой индустрии, индустрии впечатлений, включающей не только социально-культурный сервис (музеи, театры, библиотеки), но и туризм, ресторанный бизнес, индустрию красоты и пр. Впечатления сопровождают производство и потребление любого продукта культурной сферы, и они всегда личностны [11].

В современном обществе культура становится одним из стратегических факторов социальноэкономического прогресса. В широком смысле культура представляет собой систему исторически развивающихся надбиологических программ человеческой жизнедеятельности, обеспечивающих воспроизводство и изменение социальной жизни во всех её основных проявлениях [12]. В отраслевом смысле культура представляет собой особую отрасль народного хозяйства. Особенность отрас- ли заключается в том, что она удовлетворяет специфическую группу человеческих потребностей, т. е. культурных потребностей, особым способом. Деятельность в отраслях культуры направлена на всестороннее воспитание человека, при этом используются средства, восприятие которых осуществляется добровольно, с учетом интересов личности и свободного времени.

Сферу культуры как область хозяйственной деятельности начали изучать еще в 50-е гг. XX в. $\mathrm{C}$ тех пор культура как область человеческой деятельности постепенно, но неуклонно стала принимать формы экономической деятельности. С экономической точки зрения культуру следует рассматривать в двух аспектах. С одной стороны, деятельность в сфере культуры направлена на создание определённого продукта (спектакля, музыки, фильма и пр.), который может быть продан и куплен, т. е. может выступать в качестве товара. С другой стороны, произведенные в сфере культуры продукты при их потреблении оказыва- 
ют благотворное влияние на духовный и нравственный облик человека, на формирование гуманистического отношения к окружающему миру [13]. Следует также отметить, что продукты культурного назначения обладают специфическим потребительским эффектом, а именно несут определенные впечатления, эмоциональные переживания. При этом одни и те же продукты сферы услуг получают различную оценку различными потребителями в зависимости от их системы вкусов, предпочтений и культурного уровня.

В силу особой специфики культурной деятельности развитие сферы культуры требует активной государственной поддержки. Расходы бюджета на культуру позволяют государству поддерживать, развивать и совершенствовать систему социально-культурного обеспечения населения. Эти расходы играют важную роль как в социальном развитии общества, так и в обеспечении его экономического прогресса. Их экономическое значение связано с опосредованным влиянием на общественное производство, так как они способствуют улучшению качественного состава трудовых ресурсов, формируют условия для повышения производительности труда. В связи с этим в подавляющем большинстве государств бюджетное финансирование является ведущей формой государственной поддержки культурной деятельности. Основной формой финансирования социально-культурной сферы в Российской Федерации является бюджетное финансирование, осуществляемое в соответствии с законодательством РФ и ее субъектов. На сегодняшний день функциони- рование сферы культуры в нашей стране регламентируется прежде всего Гражданским, Бюджетным и Налоговым кодексами.

Статистические данные подтверждают, что за более чем двадцатилетнюю историю российского суверенитета расходы на культуру не претерпели значительных изменений как по доле в совокупных расходах консолидированного бюджета Российской Федерации, так и в общем объеме ВВП. При финансировании сферы культуры в нашей стране все еще сохраняется «остаточный» принцип, не предполагающий учета реальных потребностей отрасли в ее поддержке и дальнейшем развитии. Все еще предпринимаются попытки увязать бюджетные средства, выделяемые на культуру, с результатами культурной деятельности.

Как следует из данных рис. 1, расходы на финансирование культуры, кинематографии и СМИ в 1990-2010 гг. составляли 0,5-0,75 \% ВВП, а их доля в общих расходах консолидированного бюджета страны - 2-2,5 \%. Расходы на культуру, кинематографию и СМИ в сопоставимых ценах (2000 г.) росли за рассматриваемый период вплоть до 2008 г., причем уровень 1991 г. был преодолен только в 2004 г. Начиная с 2008 г. наметилась тенденция к снижению объемов финансирования сферы культуры в сопоставимых ценах.

Данные таблицы 2 позволяют говорить об отсутствии улучшений в финансирования сферы культуры. Доля расходов на культуру и кинематографию в 2011-2016 гг. составляла 0,5-0,6 \% ВВП, а в общих расходах консолидированного бюджета страны - 1,3-1,5 \%. Приходится кон-

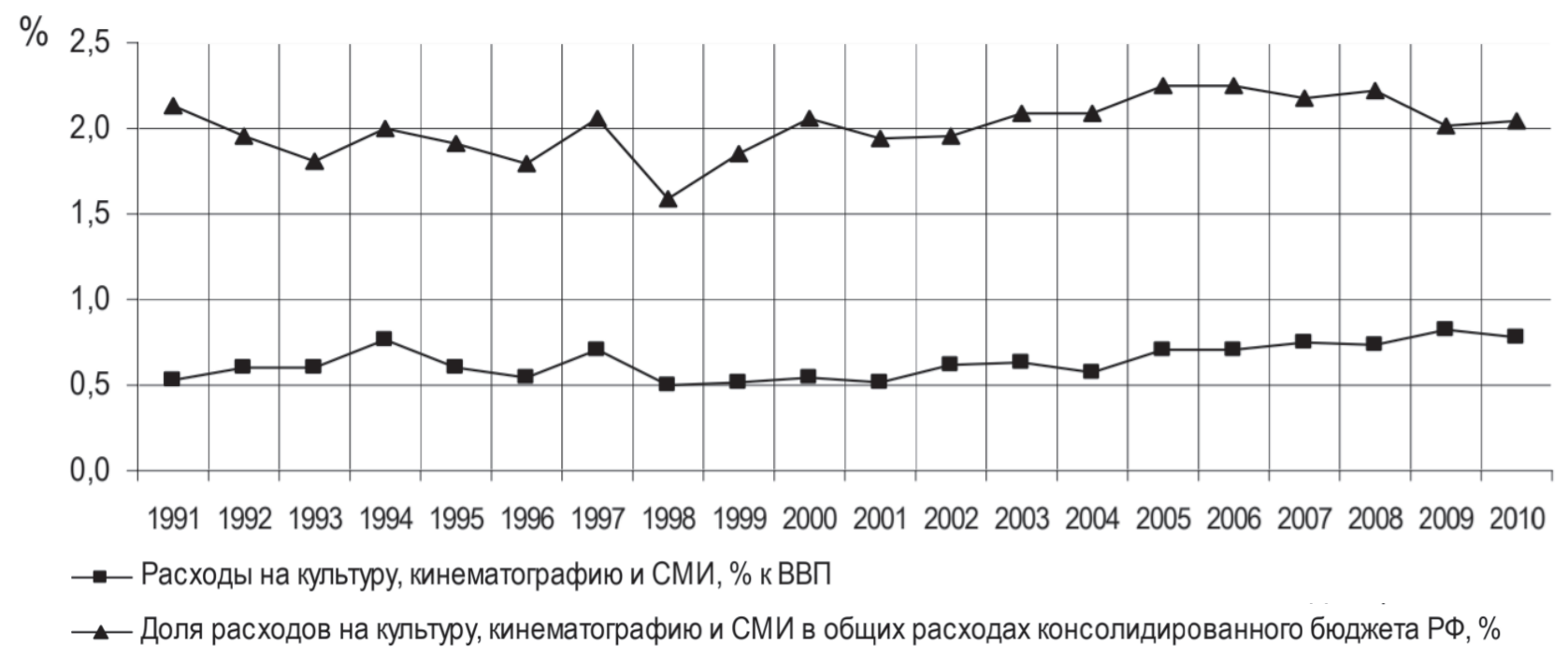

Puc. 1. Доля расходов на культуру, кинематографию и СМИ в ВВП и общих расходах консолидированного бюджета РФ, \% [14] 
Расходь консолидированного бюджета РФ на культуру и кинематографию [15-17]

\begin{tabular}{|l|c|c|c|c|c|c|}
\hline \multicolumn{2}{|c|}{ Показатель } & \multicolumn{5}{c|}{ Год } \\
\cline { 2 - 8 } & 2011 & 2012 & 2013 & 2014 & 2015 & 2016 \\
\hline Расходы на культуру и кинематографию, млрд руб. & 310,6 & 340,2 & 377,0 & 410,0 & 395,6 & 422,8 \\
\hline Удельный вес в расходах бюджета, \% & 1,6 & 1,5 & 1,5 & 1,5 & 1,335 & 1,4 \\
\hline Удельный вес в ВВП, \% & 0,6 & 0,6 & 0,6 & 0,6 & 0,5 & 0,5 \\
\hline
\end{tabular}

статировать, что в анализируемом периоде снизилась значимость расходов на культуру и кинематографию.

По объективным законам, известным всему миру, расходы на культуру должны только расти. Как следует из данных рис. 2, в течение 20082016 гг. номинальные расходы консолидированного бюджета страны на культуру устойчиво растут. Однако в реальном выражении (в ценах 2008 г.) значение названного показателя в 2011-2016 гг. так и не достигают уровня 2008 г.

В сравнении с экономически развитыми странами финансирование культуры в России осуществляется не на должном уровне. Об этом свидетельствуют как абсолютные, так и относительные цифры. Эксперты фиксируют значительное сокращение в России бюджетных расходов на культуру в расчете на душу населения в сравнении со многими странами, входящими в ОЭСР. Если в 2013 г. на каждого россиянина приходилось по 62 евро, то в 2014 г. - 55,2 евро, в 2015 г. - 39,8 евро. Для сравнения: в Норвегии в 2015 г. этот показатель составлял 563,8 евро, в Исландии 504,4 евро, в Германии - 169,8 евро, в Латвии 142,6 евро, в Румынии - 51,7 евро [18]. Ничтожно мала в ВВП нашей страны доля расходов, направляемых на финансирование культуры. Для сравнения: государственное финансирование по статье «Отдых, культура и религия» в 2015 г. в Дании $1,8 \%$, в Нидерландах - 1,4 \%, во Франции - 1,3\%, в Испании - 1,2\%, в Италии - 0,8 \%, в среднем по Евросоюзу - 1,0 \% [19].

Общей тенденцией социально-экономического развития большинства западных государств является стремление капитализировать культуру, превратить ее из дотационного в прибыльный сектор национальной экономики. Эта тенденция начинает все отчетливее проявляться и в России. Экономика впечатлений интенсивно развивается и в нашей стране. По состоянию на 2018 г. в Списке всемирного наследия ЮНЕСКО насчитывается 1092 объекта, из которых 28 имеют в описании пометку «Российская Федерация» [20]. В течение 2000-2016 гг. в России на 19 \% увеличилось чис-

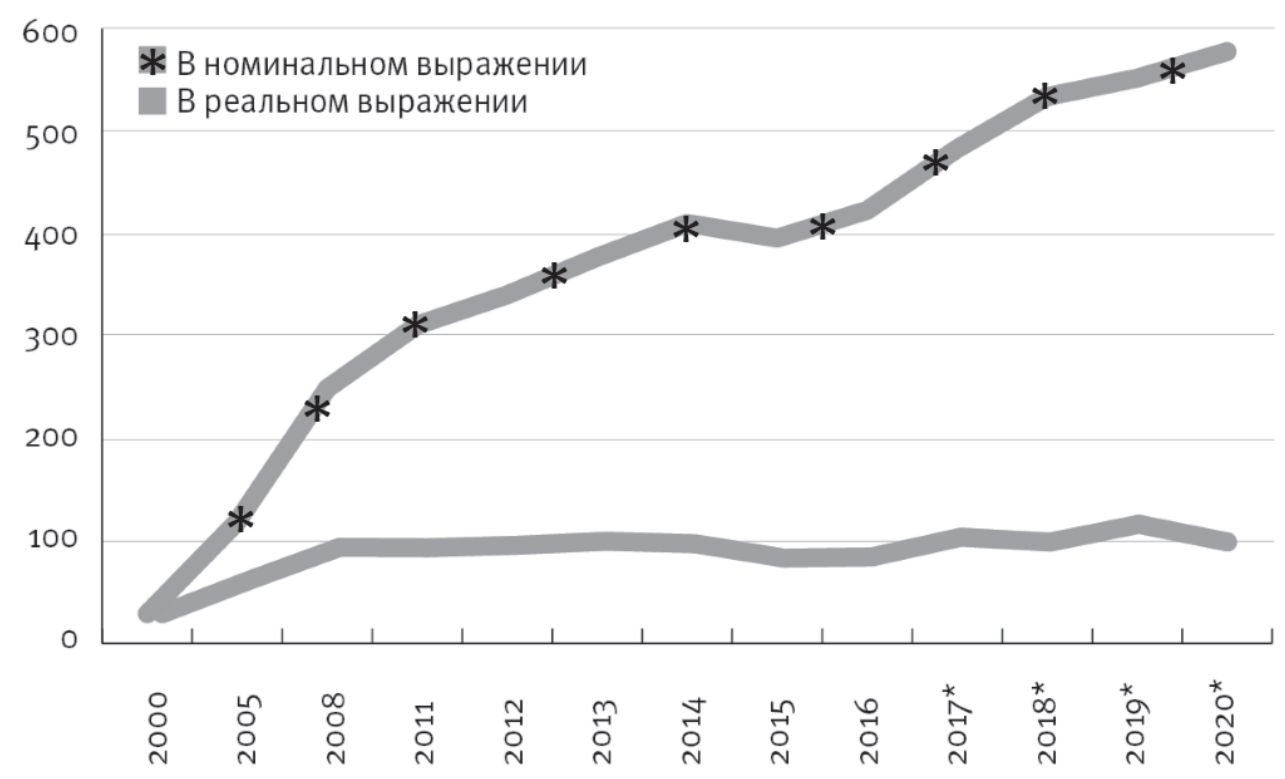

Puc. 2. Расходы консолидированного бюджета РФ на культуру в номинальном и реальном выражениях, млрд руб. [18] 
Сфера культуры и досуга как основная составляющая экономики впечатлений

Т а бл и ц а 3

Динамика численности театров и музеев в России в 1995-2016 г2. [21-22]

\begin{tabular}{|l|c|c|c|c|c|c|c|c|c|}
\hline \multicolumn{1}{|c|}{ Показатель } & \multicolumn{7}{c|}{ Год } \\
\cline { 2 - 10 } & 1995 & 2000 & 2005 & 2006 & 2007 & 2008 & 2014 & 2015 & 2016 \\
\hline Число театров - всего & 470 & 547 & 588 & 590 & 594 & 586 & 661 & 665 & 651 \\
\hline Численность зрителей театров: & & & & & & & & & \\
\hline всего, млн человек & 31,6 & 30,8 & 28,0 & 28,6 & 29,3 & 30,4 & 37,2 & 38,1 & 38,8 \\
\hline на 1000 человек населения & 213 & 210 & 196 & 201 & 206 & 214 & 255 & 260 & 265 \\
\hline Число музеев (включая филиалы) - всего & 1725 & 2047 & 2285 & 2368 & 2468 & 2495 & 2731 & 2758 & 2742 \\
\hline Число посещений музеев: & & & & & & & & & \\
\hline всего, млн & 75,4 & 73,2 & 75,6 & 79,2 & 78,8 & 80,8 & 102,7 & 119,0 & 123,5 \\
\hline на 1000 человек населения & 508 & 499 & 528 & 556 & 555 & 569 & 703 & 813 & 8942 \\
\hline
\end{tabular}

ло театров (открылось 104 театра), а численность музеев возросла на 33,4 \% (открылось 695 музеев) (табл. 3). Следует отметить и рост посещаемости театров на 25,9\% (30,8 млн чел. в 2000 г. и 38,8 млн чел. в 2016 г.), а музеев - на 68,7\% (73,2 млн чел. в 2000 г. и 123,5 млн чел. в 2016 г.).

Спрос на досуг, отдых и культуру в нашей стране стабильно высок, что подтверждает структура расходов россиян. Как следует из данных табл. 4 , доля расходов россиян на организацию отдыха и культурные мероприятия в общей структуре их расходов составляет в среднем 6,5 \%. Для сравнения: на здравоохранение у соотечественников уходит 2,5-3\% от совокупных расходов, на образование - 1,5-2 \%. Иными словами, досуг представляет собой весьма заметную статью расходов. В значительной степени она зависит от уровня благосостояния населения, сокращаясь при его ухудшении. В кризисные годы доля расходов на культуру и отдых в расходах населения страны составляла 4,5-4,7 \%, а в благополучные достигала 7-7,2 \%. В течение 2000-х гг. эта статья расходов устойчиво росла и достигла своего максимального значения в 2008 г., составив 7,7 \%. В последующие годы отмечается падение доли расходов на культуру и досуг, достигнувший в 2016 г. 6,7 \%. Следует отметить, что 10 \% самых обеспеченных россиян в 2005 г. тратили на досуг, отдых и культуру 7,6 \% своего дохода, в 2013 г. - 7,0 \%, в 2016 г. $8,9 \%$. При этом $10 \%$ наименее обеспеченных соотечественников могли себе позволить потратить на отдых и культурные мероприятия только 2,5 \% своего дохода в 2005 г., 3,1 \% - в 2013 г., $2,7 \%$ - в 2016 г.

В целом Россия находится в тренде, близком к странам с высоким уровнем социально-эконо- мического развития. В последних уровень расходов на организацию отдыха и культурные мероприятия существенно выше. Для сравнения: в 2016 г. данная статья расходов составила в Великобритании 11,1 \%, Нидерландах - 10,8 \%, Финляндии - 10,5\%, Германии - 9,1 \%, Франции $8,5 \%$, Болгарии - 7,8 \%, Италии - 6,6 \%, Португалии - 6,1 \%. В среднем по Европейскому союзу (28 стран) доля расходов на культуру и досуг составляла 8,5\% \% 18$]$.

Экономика, выступая в качестве необходимой предпосылки общественной жизни, требует для своего нормального функционирования определенные условия гуманитарного порядка. Сегодня стала очевидной роль культуры в экономических отношениях. В дальнейшем эта роль будет только возрастать. В контексте становления экономики впечатлений к культуре следует относится как к ресурсу новой экономики и агенту развития. Следует отметить и все большую роль досуга в современном мире. Люди предпочитают досуг работе, они хотят иметь как можно больше свободного времени. Развитие досуга вошло в русло развития многих отраслей современной экономики, стало причиной формирования инфраструктуры досуга в ее современном масштабе. Разумеется, в мире, где имущественное неравенство лишает большую часть жителей планеты возможности ознакомиться с достижениями культуры (как классическими, так и современными), где половина стран только встала на путь индустриализации, товарная экономика будет еще долго иметь доминирующее значение. Однако для развитых стран, проходящих этап деиндустриализации и цифровизации, ведущую роль будет играть экономика впечатлений и сфера культуры как ее важнейшая составляющая. 
Структура потребительских расходов домашних хозяйств в 2001-2016 г2., \% [15-17]

\begin{tabular}{|c|c|c|c|c|c|c|c|c|c|c|c|c|c|}
\hline \multirow[b]{2}{*}{ Показатель } & \multicolumn{13}{|c|}{ Год } \\
\hline & 2001 & 2002 & 2003 & 2004 & 2008 & 2009 & 2010 & 2011 & 2012 & 2013 & 2014 & 2015 & 2016 \\
\hline $\begin{array}{l}\text { Потребительские расходы - } \\
\text { всего }\end{array}$ & 100 & 100 & 100 & 100 & 100 & 100 & 100 & 100 & 100 & 100 & 100 & 100 & 100 \\
\hline \multicolumn{14}{|l|}{ в том числе: } \\
\hline $\begin{array}{l}\text { на продукты питания и без- } \\
\text { алкогольные напитки }\end{array}$ & 45,8 & 41,7 & 37,7 & 36,0 & 29,1 & 30,5 & 29,6 & 29,5 & 28,1 & 27,7 & 28,5 & 32,1 & 32,3 \\
\hline $\begin{array}{l}\text { алкогольные напитки, табач- } \\
\text { ные изделия }\end{array}$ & 3,6 & 3,2 & 3,2 & 3,0 & 2,3 & 2,4 & 2,4 & 2,5 & 2,5 & 2,6 & 2,8 & 3,0 & 3,1 \\
\hline одежду и обувь & 13,6 & 13,5 & 12,6 & 11,6 & 10,4 & 10,4 & 10,8 & 10,1 & 10,1 & 9,5 & 8,9 & 9,2 & 9,2 \\
\hline $\begin{array}{l}\text { жилищные услуги } \\
\text { электроэнергию, I } \\
\text { виды топлива }\end{array}$ & 7,1 & 8,7 & 10,5 & 10,8 & 10,4 & 10,8 & 11,3 & 11,4 & 10,9 & 10,5 & 10,3 & 10,8 & 11,3 \\
\hline $\begin{array}{l}\text { предметы домашнего обихо- } \\
\text { да, бытовую технику и уход } \\
\text { за домом }\end{array}$ & 6,1 & 6,0 & 7,3 & 6,9 & 7,5 & 7,0 & 6,2 & 6,5 & 6,3 & 6,7 & 6,3 & 5,5 & 5,9 \\
\hline здравоо & 2,1 & 2,3 & 2,2 & & 2,9 & 3,1 & 3,2 & 3,5 & 3,4 & 3,6 & 3,6 & 3,7 & 3,6 \\
\hline транспс & 7 , & 9 & & 10,2 & 15,5 & 13,4 & 14,9 & 15,9 & 17,3 & 7,7 & 17,8 & 14,4 & 13,3 \\
\hline связь & 1,4 & 1,8 & 2,4 & 2,9 & 3,7 & 3,8 & 3,8 & 3,7 & 3,5 & 3,4 & 3,4 & 3,3 & 3,3 \\
\hline $\begin{array}{l}\text { организацию отдыха и куль- } \\
\text { турные мероприятия }\end{array}$ & 4,7 & 4,8 & 6,0 & 6,3 & 7,7 & 7,3 & 6,8 & 6,8 & 6,9 & 7,2 & 7,1 & 6,7 & 6,7 \\
\hline образование & 1,2 & 1,5 & 1,3 & 1,7 & 1,6 & 1,5 & 1,3 & 1,2 & 1,3 & 1,0 & 1,0 & 0,9 & 0,8 \\
\hline гостиницы, кафе и рестораны & 2,6 & 2,5 & 3,1 & 3,5 & 3,0 & 3,4 & 3,4 & 3,2 & 3,4 & 3,7 & 3,6 & 3,5 & 3,5 \\
\hline другие товары и услуги & 4,1 & 4,1 & 4,5 & 4,7 & 5,9 & 6,4 & 6,2 & 6,0 & 6,3 & 6,5 & 6,7 & 6,9 & 7,0 \\
\hline
\end{tabular}

\section{ЛИТЕРАТУРА}

1. Пекар В. Введение в экономику впечатлений / B. Пекар. - URL: http://pekar.in.ua/ExperienceEconomics. htm

2. Бендиков М. А. Рынки высокотехнологичной продукции : тенденции и перспективы развития / М. А. Бендиков, И. Э. Фролов // Маркетинг в России и за рубежом. - 2001. - № 2. - URL: https://www.cfin.ru/ press/marketing/2001-2/02.shtml

3. Льгина Н. И. Особенности развития экономики впечатлений / Н. И. Лыгина, Н. А. Паршиков, О. В. Рудакова // Вестник ОрелГИЭТ. - 2018. - № 4 (46). C. $154-160$.

4. Тимошенко A. В. Развитие организационной структуры как основной фактор системной конкурентоспособности предприятия / А. В. Тимошенко // Вестник Российской академии естественных наук. - 2014. № 3. - C. 53-55. - URL: http://raen.info/upload/000/ vestnik/2014/3/53-55.pdf.

5. Пайн Д. Б. Экономика впечатлений. Работа - это театр, а каждый бизнес - сцена / Д. Б. Пайн, Д. Х. Гилмора. - М. : Вильямс, 2005. - 171 с.

6. Pine J. B. The Experience Economy : Work is Theatre \& Every Business a Stage / J. B. Pine, J. H. Gilmore. Boston : Harvard Business School Press, 1999.

7. Поротникова Н. А. Экономика впечатлений и управление опытом потребителей на ресторанном рын- ке / Н. А. Поротникова // NAUKARUS. - URL: http:// naukarus.com/ekonomika-vpechatleniy-i-upravlenieopytom-potrebiteley-na-restorannom-rynke

8. List of Countries by GDP Sector Composition // Statistics Times. - URL: https://statisticstimes.com/ economy/countries-by-gdp-sector-composition.php

9. GDP - Composition, by sector of origin // Central Intelligence agency. - URL: https://www.cia.gov/library/ publications/the-world-factbook/fields/2012.html

10. Лыгина Н. И. Экономика впечатлений в России: роль сферы культуры и досуга / Н. И. Лыгина, Н. А. Паршиков, О. В. Рудакова // Известия Юго-Западного университета. Серия : Экономика, социология, менеджмент. - 2019. - № 3 (32). - Т. 9. - С. 8-17.

11. Новосельская В. В. Культурное пространство территории как ресурс экономики впечатлений / B. В. Новосельская // CYBERLENINKA. - URL: https:// cyberleninka.ru/article/v/kulturnoe-prostranstvo-territoriikak-resurs-ekonomiki-vpechatleniy

12. Культура // Гуманитарные технологии: аналитический портал. - URL: http:/gtmarket.ru/concepts/ 6859

13. Богомазов Г. Г. Сфера культуры как объект изучения экономической науки / Г. Г. Богомазов, Д. А. Давыдова // Вестник СПбГУ. Экономика. - 2017. - Т. 33. Вып. 3. - C. 415-432. - URL: https://dspace.spbu.ru/ bitstream/11701/8458/1/04-Bogomazov.pdf 
14. Музычук В. Ю. Основные тенденции культурной политики в современной России / В. Ю. Музычук // Россия и современный мир. - 2012. - № 4 (77). - С. $72-$ 83. - URL: http://rossovmir.ru/files/2012_\%D0\%A0\% D0\%A1\%D0\%9C_4.pdf

15. Социальное положение и уровень жизни населения России. 2017 : стат. сб. - М. : Росстат, 2017. - 332 с.

16. Социальное положение и уровень жизни населения России. 2015 : стат. сб. - М. : Росстат, 2015. $311 \mathrm{c}$.

17. Социальное положение и уровень жизни населения России. 2013 : стат. сб. - М. : Росстат, 2013. 327 c.

Орловский государственный университет экономики и торговли

Льгина Н. И., доктор экономических наук, профессор, профессор кафедры «Маркетинг и торговое дело»

E-mail:lyginani@mail.ru

Орловский государственный институт кульmypbl

Паршиков Н. А., доктор педагогических наук, nрофессор, ректор

E-mail:ogiik@orel.ru

Российская академия народного хозяйства и государственной службб при Президенте Российской Федераџии (Среднерусский институт управления)

Орловский государственный институт кульmypsi

Рудакова О. В., доктор экономических наук, профессор, профессор кафедры «Менеджмент и государственное управление», профессор кафедры «Экономика и управление»

E-mail: rudakova71@yandex.ru
18. Буторина Е. Бизнес по продаже воспоминаний / E. Буторина // Профиль. - 2018. - 24 ноября. - URL: https://profile.ru/obsch/item/126313-biznes-po-prodazhevospominanij

19. General government expenditure by function (COFOG). 2015 // EUROSTAT. - URL: http://appsso. eurostat.ec.europa.eu/nui/submitViewTableAction.do

20. World Heritage List // UNESCO. - URL: http:// whc.unesco.org/en/list

21. Платное обслуживание населения в России. 2009 : стат. сб. - М. : Росстат, 2009. - 367 с.

22. Платное обслуживание населения в России. 2017 : стат. сб. - М. : Росстат, 2017. - 110 с.

Oryol State University of Economics and Trade

Lygina N. I., Doctor of Economic Sciences, Professor

E-mail:lyginani@mail.ru

Oryol State Institute of Culture

Parshikov N. A., Doctor of Pedagogics, Professor, Rector

E-mail:ogiik@orel.ru

Branch of the Russian Presidential Academy of National Economy and Public Administration (Central Russian Institute of Management)

Oryol State Institute of Culture

Rudakova O. V., Doctor of Economic Sciences, Professor

E-mail: rudakova71@yandex.ru 